\title{
Gene-Environment Interaction Research and Transgenic Mouse Models of Alzheimer's Disease
}

\author{
L. Chouliaras, ${ }^{1}$ A. S. R. Sierksma, ${ }^{1}$ G. Kenis, ${ }^{1}$ J. Prickaerts, ${ }^{1}$ M. A. M. Lemmens, ${ }^{1}$ \\ I. Brasnjevic, ${ }^{1}$ E. L. van Donkelaar, ${ }^{1}$ P. Martinez-Martinez, ${ }^{1}$ M. Losen, ${ }^{1}$ M. H. De Baets, ${ }^{1}$ \\ N. Kholod, ${ }^{1}$ F. W. van Leeuwen, ${ }^{1}$ P. R. Hof, ${ }^{2}$ J. van Os, ${ }^{1,3}$ H. W. M. Steinbusch, ${ }^{1}$ \\ D. L. A. van den Hove, ${ }^{1,4}$ and B. P. F. Rutten ${ }^{1}$
}

${ }^{1}$ School for Mental Health and Neuroscience (MHeNS), Faculty of Health, Medicine and Life Sciences, European Graduate School of Neuroscience (EURON), Maastricht University Medical Centre, P.O. Box 616, 6200 MD, Maastricht, The Netherlands

${ }^{2}$ Department of Neuroscience, Mount Sinai School of Medicine, One Gustave L. Levy Place, New York, NY 10029, USA

${ }^{3}$ Division of Psychological Medicine, Institute of Psychiatry, De Crespigny Park, London SE5 8AF, UK

${ }^{4}$ Department of Psychiatry, Psychosomatics and Psychotherapy, University of Würzburg, 97080 Würzburg, Germany

Correspondence should be addressed to B. P. F. Rutten, b.rutten@np.unimaas.nl

Received 1 November 2010; Accepted 25 November 2010

Copyright ( $) 2010$ L. Chouliaras et al. This is an open access article distributed under the Creative Commons Attribution License, which permits unrestricted use, distribution, and reproduction in any medium, provided the original work is properly cited.

In the published version of this paper, the following corrections should be introduced:

(1) On the first page, it should be mentioned that "L. Chouliaras and A. S. R. Sierksma are joint-first authors."

(2) At page 11, Section 7 "Electromagnetic field exposure", line 41: it was incorrectly stated that “..., decreased transthyretin levels have also been found in blood serum of long-term wireless phone." The correct text should read "..., increased transthyretin levels have also been found in blood serum of longterm wireless phone." 


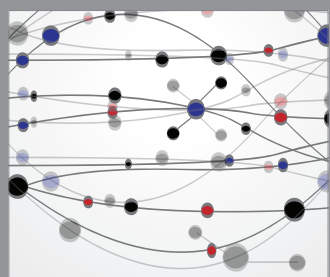

The Scientific World Journal
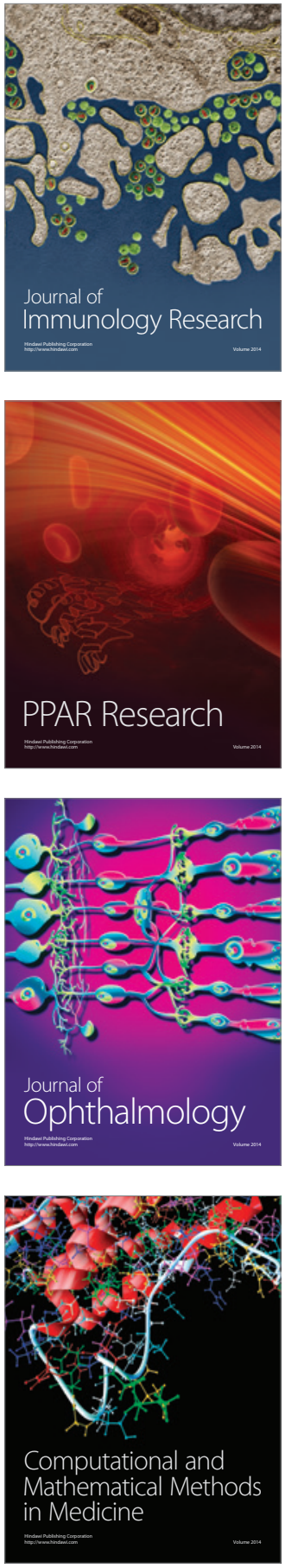

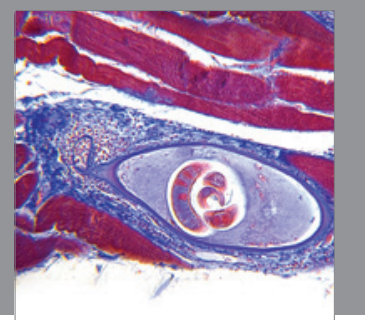

Gastroenterology

Research and Practice
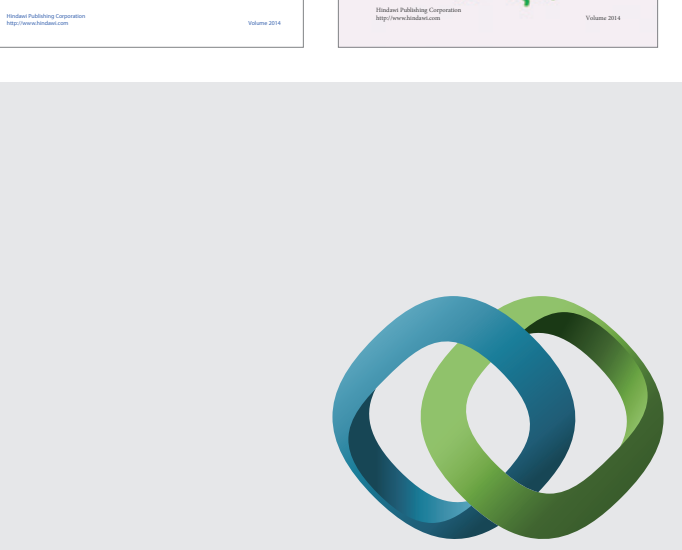

\section{Hindawi}

Submit your manuscripts at

http://www.hindawi.com
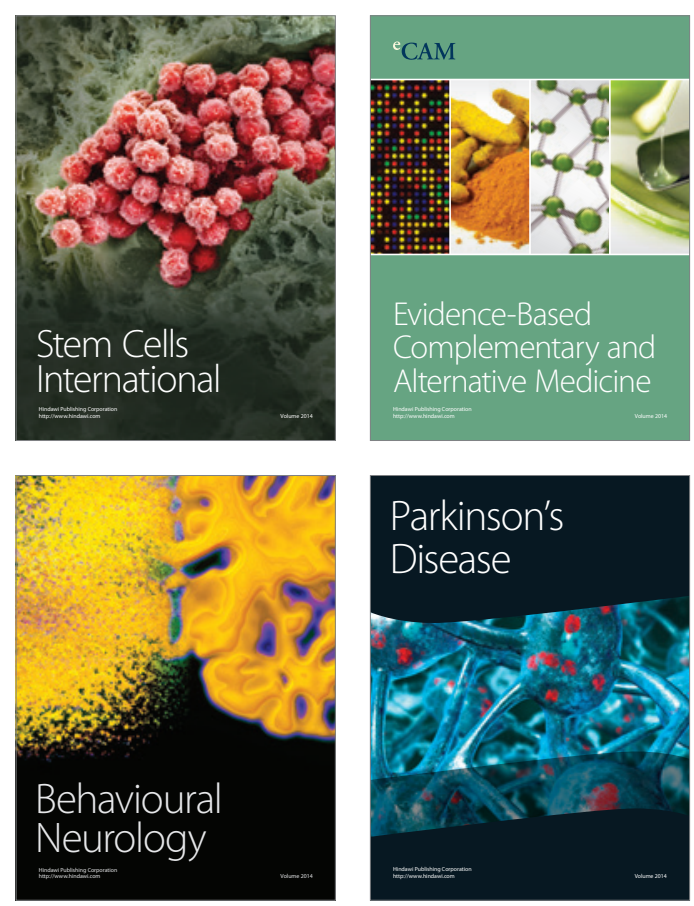

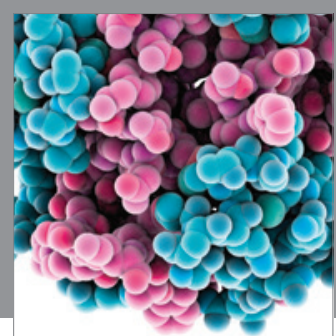

Journal of
Diabetes Research

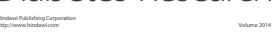

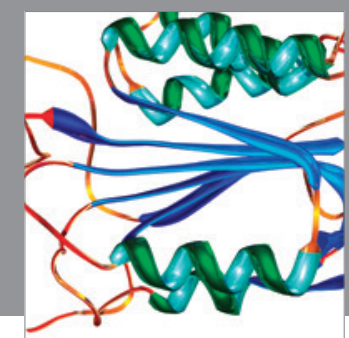

Disease Markers
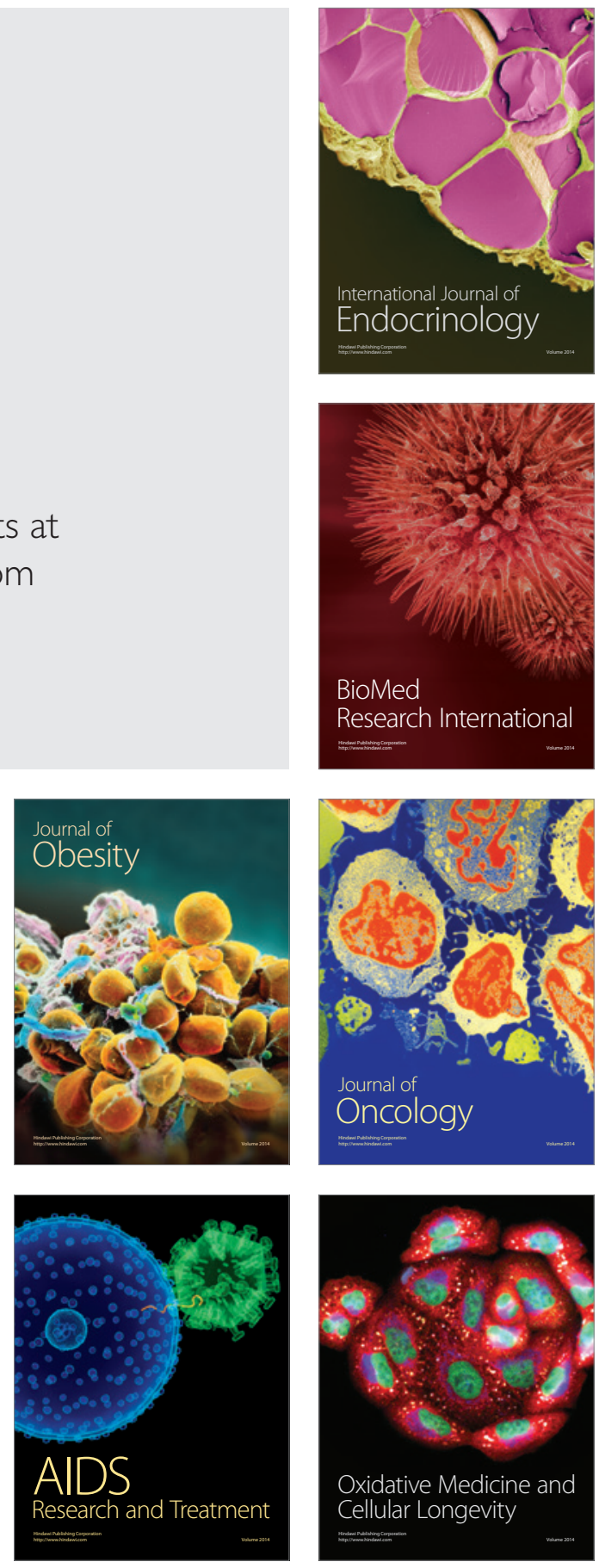